\title{
Organochlorine residues in human breast milk: analysis through a sentinel practice network
}

\author{
M Schlaud, A Seidler, A Salje, W Behrendt, F W Schwartz, M Ende, A Knoll, \\ C Grugel
}

\begin{abstract}
Study objective - The study aimed to assess through a sentinel practice network the validity of data on levels of organochlorine residues in human milk along with personal, lifestyle, and exposure variables of breastfeeding women; to compare the results of this new approach with those of the Lower Saxony breast milk surveillance programme; and to test hypotheses on potential determinants of contamination levels.

Design - Eligible women were enrolled into this cross sectional study by a network of 51 paediatric practices when bringing their babies for a U3 infant screening examination (4th to 6th week after delivery). Lifestyle and exposure factors were obtained by questionnaire. All milk samples were analysed for hexachlorocyclohexane, hexachlorbenzole, DDT, dieldrin, polychlorinated biphenyls (PCB) and heptachlor; half the samples were also analysed for dioxin. Analytic statistics were computed using polychotomous logistic regression (PLR).
\end{abstract}

Setting - The study was conducted in Lower Saxony, Germany, from summer 1992 to summer 1993.

Participants - Altogether 156 primiparous, breast feeding German women, aged 25-35 years, who had been born and had grown up in West Germany, were studied.

Main results - Compared with the regular programme, participants in this study had their milk analysed sooner after delivery and were more likely to have grown up in rural areas, less likely to have been exposed to hazardous substances, less likely to have a diet of health food, and slightly less likely to be a smoker at the time of the study. Breast milk contamination levels were comparable in both studies, and in all but two cases well below the tolerable concentrations established by the Deutsche Forschungsgemeinschaft (German Research Fellowship). After adjustment for potential confounders using polychotomous logistic regression, there were statistically significant positive associations between breast milk contamination and age (PCB, test for trend: $p=0.006$ ), average dietary fat intake per week (dioxin, $p=0 \cdot 01$ ), and proximity of residence to hazardous sites (dioxin, $\mathbf{p}<0.05$ ), and negative associations between residue levels and relative body weight at the time of the study (PCB; $p<0.0001)$ and difference in body weight (weight minus weight before the pregnancy; PCB, $p=0.0002$ ), respectively.

Conclusions - Sentinel practice networks are a feasible and low-biased approach to population based breast milk studies. The contamination levels and associations found are biologically plausible and comparable with the results of other studies. To reduce organochlorine residue levels in human milk in the short term, breastfeeding women should be advised not to try to reduce their weight until after lactation. Public promotion of a lower dietary fat intake may reduce the lifetime accumulation of organochlorine compounds in the human body fat tissue in the long term, resulting in lower concentrations in breast milk as well.

( $(\mathcal{E}$ EpidemiolCommunity Health 1995;49(Suppl 1):17-21)

Mother's milk is considered the best nutrition for the growing infant. Not only does it provide all the necessary nutrients and antibodies ${ }^{1}$ in adequate combination, breast feeding is also an important social factor in the relationship between mother and child.

In numerous scientific studies worldwide, residues of persistent organochlorine compounds, especially pesticides and dioxins, have been detected in human breast milk. This has caused much public concern raising questions about whether breast feeding might be harmful to infants. Recent studies indicate that there may be biological effects of organchlorine breast milk contaminants in children, ${ }^{23}$ even when residue levels are below those concentrations that are currently regarded as tolerable. Since there is a strong correspondence between organochlorine contamination levels in breast milk and in maternal body fat tissue, ${ }^{45}$ possible health risks for adults must also be considered. ${ }^{6}$

Even if there is no unequivocal association known to the scientific community between the pesticide levels actually found in human milk and bad health, ${ }^{7}$ all chemicals that are not normal constituents of human milk should be considered undesirable contaminants. ${ }^{8}$ In many studies a decrease in the levels of certain pesticides (for example, DDT) and, to a lesser extent, of polychlorinated biphenyls (PCB) has been established. This is attributed to the prohibition or restriction of these compounds. ${ }^{9}$ 
Further surveillance of contamination levels in human breast milk, however, is essential.

In Lower Saxony, a state of the Federal Republic of Germany, mothers have been able to have their milk analysed for organochlorine compounds for many years. In the Lower Saxon breast milk surveillance programme (from here on referred to as the "regular programme"), chemical analyses are done for self referred women, who may be a subpopulation with higher or lower risk of exposure than the general population. Moreover, very limited data are obtained on lifestyle and other important characteristics of the mothers and thus no hypotheses on associations can be generated or tested.

In many European countries, sentinel practice networks have been established as an epidemiological tool in the ambulatory health care system. In these networks, office based physicians cooperate in monitoring defined events among their patients (for example, influenza, mumps, asthma attacks). Sentinel systems can also be used as an approach to various types of epidemiological studies in the population served. After adequate analysis, the data may indicate spatial and temporal trends in event frequencies and aetiological hypotheses can be generated or tested.

Since 1991, the MORBUS sentinel practice network has been operational in three regions of Lower Saxony. MORBUS is an acronym for "Modellversuch regionale Beobachtungspraxen zwecks Erhebung umweltbezogener Gesundheitsstörungen" (pilot project to establish regional sentinel practices for the assessment of data on environment related health problems). Since the start of the project, which is being funded by the German Federal Ministry of Science and Technology, a number of health conditions have been monitored consecutively in both children and adults.

To overcome the limitations of the regular programme, we carried out a study on organochlorine residue levels in human milk using the MORBUS sentinel practice network as a new and possibly less biased approach to the population of breastfeeding mothers.

\section{Methods}

From the summer of 1992 to the summer of 1993, 51 paediatric practices took part in this study. The practices had been recruited into the sentinel network as a representative random sample of all paediatric practices in the study regions.

In accordance with recommendations for standardised entrance criteria for breast milk studies, ${ }^{10}$ eligible women had to be:

- Primiparous,

- Breast feeding one child,

- Enrolled when bringing their offspring into a sentinel practice for his or her U3 infant screening examination which is scheduled for the 4 th to 6 th week after delivery,

- 25-35 years of age,

- Of German nationality and have been born and grown up in West Germany.
The paediatricians had to ask eligible women to participate in the study, obtain informed consent and provide the women with a set of study material. At home, participants had to answer a detailed 14 page questionnaire about their height and weight, eating habits, other lifestyle variables and potential sources of exposure. They also had to produce a breast milk sample $(200 \mathrm{ml})$ which was sent in a sealed glass jar to the laboratory. Participants were informed about the results of their breast milk analyses by their doctors.

Chemical analyses were performed in the laboratories of the Staatliches Lebensmitteluntersuchungsamt Oldenburg, which regularly takes part in the WHO quality control studies. In order to exclude any contamination in the laboratory, all adsorbents and glass devices were specially cleaned, and all adsorbents and solvents were checked for potential contamination using gas chromatography/mass spectrometry (GCMS) before use.

All milk samples were analysed for hexachlorocyclohexane $(\mathrm{HCH})$, hexachlorbenzole (HCB), dichlorodiphenyltrichlorethane (DDT), dieldrin, polychlorinated biphenyls (PCB), and heptachlor residues. After centrifugation of the milk samples, elution of the fat fraction, and adequate processing and clean up, analyses for all substances mentioned above were performed on a gas chromatography system with an electron capture detector. Because of cost restrictions, only every second milk sample could also be analysed for dioxins. These analyses were performed on a Finnigan MAT 95 GCMS device, which was operated in the electron impact ionisation mode with a mass resolution of 10000

From the data of the regular programme, which was run concurrently, 111 data sets from mothers who met the same criteria as those in the MORBUS project were selected and the results of both studies were compared.

Descriptive statistics of contamination levels and data from questionnaires were computed using the Statistical Package for the Social Sciences (SPSS) for Windows Release 6. From the information on the number of hazardous industries and sites (chemical plants, paint and lacquer industry, lacquer-works, iron and steel industry, mining industry, incinerating plants, oil refineries, oil or coal fuelled power stations, waste disposal sites, motorways) nearby and their proximities to the women's residence given in a check list of each questionnaire, an individual environmental exposure score was calculated. To express relative body weights of participants at the time of the study, Broca's index was used as follows:

Relative body weight $=$ body weight

(in $\mathrm{kg}$ ) - (body size (in $\mathrm{cm}$ ) -100$) \times 0.9$

Each participant's average fat intake per week was estimated from the food frequency section of the questionnaire using official information on average portion sizes ${ }^{11}$ and on mean fat content of nutrients. ${ }^{12}$

For analytic statistics of potential risk factors and breast milk contamination levels, polychotomous logistic regression (PLR) by the 
Biomedical Computer Programme (BMDP) Release 7 was used. From the distributions of both PCB and dioxin concentrations in breast milk, ordinal dependent variables were computed (level 1: >0-25\%; 2: >25-50\%; 3: >50-75\%; $4:>75-95 \%$; 5 : $>95-100 \%$ of the distribution).

\section{Results}

CHARACTERISTICS OF PARTICIPANTS

A total of 156 women with a median age of 29 years (mean age 29.5 years) entered the MORBUS study. On the average, their milk samples were produced 1.8 months after delivery when the mean weight of the mothers was $65.8 \mathrm{~kg}$ and that of the children $5028 \mathrm{~g}$.

The selected 111 participants of the regular programme had a mean age of 29.7 years. Their milk samples were produced on the average 4.4 months after delivery. The difference to the MORBUS study was statistically significant ( $t$ test: $\mathrm{p}<0.001)$. Thus, mothers' weights were lower (average $63.5 \mathrm{~kg} ; \mathrm{p}<0.04$ ) and children's weights were higher (average $6646 \mathrm{~g} ; \mathrm{p}<0.001$ ) than in the MORBUS study.

There were substantial differences in lifestyle characteristics between participants of both studies (table 1). According to self reports on questionnaires, women from the MORBUS study were much more likely to have grown up in rural areas $\left(\chi^{2}\right.$ test: $\left.p<0 \cdot 001\right)$, less likely to have been exposed to hazardous substances $(p=0.008)$, less likely to have a diet of health food $(p<0.001)$, and slightly less likely to be a smoker at the time of the study (NS). There was, however, no substantial difference in the proportion of women who had ever been abroad for longer than four weeks and could have been exposed at that time. Since there was no information in the regular programme's data indicating which countries had been visited, this could not be compared.

\section{BREAST MILK CONTAMINATION LEVELS}

In the MORBUS study, chemical analyses of all but two milk samples yielded contamination levels which were far below the tolerable concentrations established by the Deutsche Forschungsgemeinschaft (DFG; German Research Fellowship). ${ }^{13}$ In the two cases mentioned above, mothers were recommended to reduce breast feeding four months after delivery because of relatively high HCB residues. Mean levels of organochlorine residues found in the milk samples from the MORBUS study and from comparable women in the regular programme along with tolerable concentrations established by the DFG are shown in table 2 . The differences between the two studies are minimal and not statistically significant.

\section{DETERMINANTS OF CONTAMINATION LEVELS}

The results of analytic statistics are shown in table 3. Despite restricting the age to women 25-35 years, the level of PCB still increased with age (PLR adjusted for education; test for

Table 1 Self reported lifestyle characteristics of women participating in the MORBUS study and the regular progamme, respectively.

\begin{tabular}{|c|c|c|c|c|c|}
\hline & $\begin{array}{l}\text { Grown up in rural } \\
\text { area (\%) }\end{array}$ & $\begin{array}{l}\text { Exposed to } \\
\text { hazardous } \\
\text { substances (\%) }\end{array}$ & $\begin{array}{l}\text { Health food diet } \\
(\%)\end{array}$ & $\begin{array}{l}\text { Smoker at TOS } \\
(\%)\end{array}$ & $\begin{array}{l}\text { Ever been abroad } \\
\text { for } \geq 4 \text { wk (\%) }\end{array}$ \\
\hline $\begin{array}{l}\text { MORBUS } \\
\text { Regular programme } \\
\chi^{2} \text { test }\end{array}$ & $\begin{array}{l}38.5 \\
3.2 \\
\mathrm{p}<0.001\end{array}$ & $\begin{array}{l}6.4 \\
16 \cdot 5 \\
p=0.008\end{array}$ & $\begin{array}{l}0.6 \\
15.5 \\
\mathrm{p}<0.001\end{array}$ & $\begin{array}{l}8 \cdot 3 \\
14 \cdot 4 \\
p=0 \cdot 11\end{array}$ & $\begin{array}{l}12 \cdot 2 \\
14 \cdot 2 \\
p=0 \cdot 64\end{array}$ \\
\hline
\end{tabular}

* TOS $=$ time of the study

Table 2 Synopsis of tolerable concentrations established by the Deutsche Forschungsgemeinschaft ${ }^{\prime 3}$ along with mean contamination levels of breast milk samples from the MORBUS study and the regular programme in Lower Saxony, Germany (differences not statistically significant).

\begin{tabular}{|c|c|c|c|c|c|}
\hline & $\begin{array}{l}\text { Tolerable } \\
\text { concentration* } \\
\text { (mg/kg) }\end{array}$ & $\begin{array}{l}\text { MORBUS study } \\
\text { median }(\mathrm{mg} / \mathrm{kg}) \dagger\end{array}$ & No & $\begin{array}{l}\text { Regular programme } \\
\text { median }(\mathrm{mg} / \mathrm{kg}) \dagger\end{array}$ & No \\
\hline $\begin{array}{l}\text { PCDD/F (I-TEq)* } \\
\text { Total DDT } \\
\text { Dieldrin } \\
\text { Heptachlor } \\
\gamma \text {-HCH (lindan) } \\
\beta \text {-HCH } \\
\text { Total PCB } \\
\text { HCB }\end{array}$ & $\begin{array}{l}\text { (not defined) } \\
9 \cdot 60 \\
0.20 \\
1.00 \\
19 \cdot 10 \\
1.67 \\
1.90 \\
1.20\end{array}$ & $\begin{array}{r}19 \cdot 586 \\
0.380 \\
0.014 \\
0.022 \\
0.016 \\
0.045 \\
0.541 \\
0.223\end{array}$ & $\begin{array}{r}88 \\
155 \\
103 \\
115 \\
16 \\
151 \\
156 \\
155\end{array}$ & $\begin{array}{r}23 \cdot 160 \\
0.361 \\
0.014 \\
0.021 \\
0.012 \\
0.059 \\
1 \cdot 316 \\
0.149\end{array}$ & $\begin{array}{r}8 \\
109 \\
50 \\
52 \\
20 \\
99 \\
100 \\
110\end{array}$ \\
\hline
\end{tabular}

* Dioxin (international toxic equivalents)

$t$ All values are $\mathrm{mg} / \mathrm{kg}$ milk fat.

$\mathrm{PCDD} / \mathrm{F}=$ dioxin; $\mathrm{HCH}=$ hexachlorocyclohexane; $\mathrm{PCB}=$ polychlorinated biphenyls; $\mathrm{HCB}=$ hexachlorbenzole

Table 3 Determinants of polychlorinated biphenyls (PCB) and dioxin residue levels in human breast milk

\begin{tabular}{llll}
\hline & & $T$ Test for trend & \\
\cline { 3 - 4 } Independent variable & Direction of association & $P C B(n=156)$ & Dioxin $(n=88)$ \\
\hline Age & Positive & $\mathrm{p}=0.006^{*}$ & $\mathrm{p}=0.08^{*}$ \\
Relative body weight at the time of the study & Negative & $\mathrm{p}<0.0001 \dagger$ & $\mathrm{p}=0.0002 \dagger$ \\
Difference in body weight & Negative & $\mathrm{p}=0.0002 \dagger$ & $\mathrm{p}=0.03 \dagger$ \\
Average dietary fat intake per week & Positive & $\mathrm{p}=0.054 \ddagger$ & $\mathrm{p}=0.01 \ddagger$ \\
Score of environmental exposure & Positive & $\mathrm{p}=0.38 \dagger$ & $\mathrm{p}<0.05 \dagger$ \\
\hline
\end{tabular}

Method: polychotomous logistic regression (* adjusted for education; $\nmid$ adjusted for age and education; $\neq$ adjusted for age, education and relative body weight at the time of the study) 
trend: $p=0.006)$. Due to the smaller sample size, the positive association between age and dioxin levels failed to yield statistical significance (PLR, adjusted for education; test for trend: $p=0 \cdot 08)$. The relative body weight of women at the time of the study was negatively associated with breast milk residues of both PCB (PLR, adjusted for age and education; test for trend: $p<0.0001)$ and dioxin $(p=0.0002)$. The difference in body weight (weight minus weight before pregnancy) also showed a negative association with both compounds (PLR, adjusted for age and education; test for trend; PCB: $p=0.0002$; dioxin: $p=0.03$ ). The average dietary fat intake per week was significantly and positively associated with dioxin residues in breast milk (PLR, adjusted for age, education, and relative body weight at the time of study; test for trend: $p=0 \cdot 01$ ). The association between fat intake and PCB levels did not quite reach statistical significance $(p=0.054)$. Women with a higher environmental exposure score - that is, those who were more likely to live closer to hazardous industries and sites, were also more likely to have higher dioxin levels in their breast milk (PLR, adjusted for age and education; test for trend: $p<0.05)$. The current and former occupation of participants, the use of pesticides in gardening or agriculture, the use of paint or wood preservatives in homes, and visits of more than four weeks in developing or eastern countries, which are known to have higher pesticide exposure, did not turn out to be significantly associated with residue levels in breast milk.

\section{Discussion}

Conducting a breast milk study through a network of sentinel practices was a new approach and was intended to reduce potential selection bias. In the regular programme women who wish an analysis of their milk have to contact their local public health department, normally situated in towns and cities. Thus, women from rural areas and/or women who are not particularly concerned about their health can be expected to be less likely to participate in the regular programme. After comparing basic characteristics and lifestyle variables of participants from the MORBUS study and the regular programme, our results suggest that women from urban areas and women who are more likely to have been exposed to hazardous substances might be over represented in the regular programme and other breast milk studies using comparable designs. ${ }^{1415}$

However, the results of breast milk analyses in the MORBUS study differed only insignificantly from those of the regular programme. This might be at least partly explained by the weakness of the associations between exposure and contamination levels and by the small magnitude of detected residue levels. The average time between delivery and chemical analysis of the breast milk differed significantly between both studies (MORBUS 1.8 months; regular programme 4.4 months). Since there is a clear negative association between contamination levels and the period of lactation, ${ }^{1617}$ lower breast milk residue levels in the regular programme compared with the MORBUS study could have been expected. The failure to show this might be partly attributable to the higher number of women in the regular programme who were more likely to have been exposed to hazardous substances and also more likely to have grown up in urban areas. In a multivariate statistical approach, however, Lindström found no urban-rural differences in breast milk contamination levels. ${ }^{18}$

The associations found in this study between mothers' age, relative weight at the time of the study, and difference in body weight and the organochlorine contaminants in breast milk have been established in other studies too..$^{190}$ During weight reduction, organochlorine compounds accumulated in the human body fat tissue would be mobilised, resulting in higher breast milk contamination levels. Since the main pathway for lipophile organochlorine compounds into the human body is food, the association between the average dietary fat intake per week and breast milk contamination levels found in the MORBUS study is biologically plausible. Other studies, ${ }^{14}$ however, failed to show any association between nutrition and residue levels. This might be at least partly attributable to non-differential exposure misclassification due to the general difficulties in obtaining valid information on individual eating habits. ${ }^{21}$

In this study, the environmental exposure score, which indicates the proximity of the women's residence to hazardous industries and sites, was significantly associated with dioxin levels in the breast milk, but there was no significant relationship between PCB levels and environmental exposure score. Since dioxins are byproducts of many processes in industry, the association found in the MORBUS study is biologically plausible and might be due to higher environmental contamination by dioxin than by PCB. In a recent study from Russia, ${ }^{22}$ a clear association between proximity of residence to a PCB emitting industrial site and abnormally high concentrations of PCB in breast milk was found. Apart from small sample sizes and low residue levels in breast milk, the general difficulties in assessing such an association, if one exists, are exposure misclassification when using "proximity" to potentially hazardous sites to estimate level of exposure.

\section{CONCLUSIONS}

This study was able to show that sentinel practice networks are a feasible and low-biased approach for population based breast milk studies. Repeated cross sectional breast milk studies through sentinel practice networks, which exist in most European countries, ${ }^{23}$ may support continuing surveillance programmes by intensified efforts in obtaining detailed information on lifestyle and on potential sources of exposure from each participant. If there are no surveillance programmes, breast milk studies could be easily nested in existing sentinel practice networks and could be carried out at relatively low cost. 
The contamination levels and associations found in this study are comparable with results from other studies and are biologically plausible. It is reassuring that residue levels of all but two breast milk samples were well below the tolerable concentrations established by the DFG. Recent studies, however, suggest that they may be biological effects of organochlorine breast milk contaminants in children, ${ }^{23}$ even when residue levels are below those concentrations that are currently regarded as tolerable.

Our data suggest that women living close to hazardous sites may have higher levels of accumulated dioxin in their body, and thus have higher levels of dioxin residues in their breast milk. Further studies, however, are necessary. To reduce organochlorine residue levels in human milk in the short term, breastfeeding women should be advised not to try to lose weight until after lactation. Public promotion of a lower dietary fat intake may reduce the lifetime accumulation of organochlorine compounds in the human body fat tissue in the long term, resulting in lower concentrations in breast milk as well.

The reduction of organochlorine compound emission into the environment and therefore the reduction of associated health risks will remain a major public health task for the future. In support of these tasks, sentinel practice networks may be a valuable epidemiological tool for both continuing surveillance of contamination levels and for person-based analytic studies.

1 Torres O, Cruz JR. Protection against Campylobacter diarrhea: role of milk IgA antibodies against bacterial surface antigens. Acta Paediatr Scand 1993;82:835-8.

2 Koppe JG, Pluim HJ, Olie K, van Wijnen J. Breast milk, dioxins and the possible effects on the health of newborn dioxins and the possible effects on the health
infants. Sci Total Environm 1991;106:33-41.

3 Rogan WJ, Gladen BC. PCBs, DDE, and child development at 18 and 24 months. Ann Epidemiol 1991;1:407-13.

4 Stevens MF, Ebell GF, Psaila-Savona P. Organochlorine pesticides in Western Australian nursing mothers. Med $\mathcal{F}$ Aust 1993;158:238-41.

5 Kanja LW, Skaare JU, Ojwang SB, Maitai CK. A comparison of organochlorine pesticide residues in maternal adipose tissue, maternal blood, cord blood, and human milk from mother/infant pairs. Arch Environ Contam Toxicol 1992; 22

6 Falck F Jr, Ricci A Jr, Wolff MS, Godbold J, Deckers P. Pesticides and polychlorinated biphenyl residues in human breast lipids and their relation to breast cancer. Arch Environ Health 1992;47:143-6.

7 Monheit BM, Luke BG. Pesticides in Breast Milk-A Public Health Perspective. Community Health Studies 1990;3: 269-73.

8 Somogyi A, Beck H. Nurturing and breast-feeding: exposure to chemicals in breast milk. Environ Health Perspect 1993; 101:45-52.

9 Noren K. Contemporary and restrospective investigations of human milk in the trend studies of organochlorine contaminants in Sweden. Sci Total Environ 1993;139-140 (1):347-55.

10 Sim MR, McNeil JJ. Monitoring Chemical Exposure using Breast Milk: A Methodological Review. Am $f$ Epidemiol 1992;136:1-11.

11 Deutsche Gesellschaft für Ernährung. Ernährungsbericht 1988. Frankfurt am Main: Umschau Verlag, 1988.

12 Kluthe B, Kluthe R. Prodi 3 plus: Praxisorientiertes Dialogsystem für Ernährungs- und Diätberatung. Stuttgart: Wissenschaftliche Verlagsgesellschaft, 1989.

13 Deutsche Forschungsgemeinschaft (DFG). Rückstände und Verunreinigungen in der Frauenmilch. Mitteilung XII. VCH: Weinheim, 1984.

14 Lanstadtler M. Results of breast milk examinations in Northern Bavaria. Gesundheitswesen 1993;55:301-7.

15 Ehrenstorfer S, Hiebl J, Lassek E, Rappl A. Results of human milk analysis for pesticide levels in women of the south Bavarian region. Gesundheitswesen 1991;53:784-91.

16 Fürst $\mathrm{P}$, Krüger C, Memmken H-A, Groebel W. PCDD and PCDF levels in human milk - dependence on the period of lactation. Chemosphere 1989;18:439-44.

17 Skaare JU, Polder A. Polychlorinated biphenyls and organochlorine pesticides in milk of Norwegian women during chlorine pesticides in milk of Norwegian women during

18 Lindström GUM, Sjöström M, Swanson SE, Fürst P Krüger C, Memken H-A, Groebel W. Multivariate statistical approach to a data set of dioxin and furan contaminations in human milk. Bull Environ Toxicol 1988;40: 641-6.

19 Drijver M, Duikers TJ, Kromhout D, Visser TJ, Mulder P, Louw R. Determinants of polychlorinated biphenyls (PCBs) in human milk. Acta Paediatr Scand 1988;77:30-6.

20 Rogan WJ, Gladen BC, McKenney JD, et al. Polychlorinated biphenyls (PCBs) and dichlorodiphenyl dichloroethane (DDE) in human milk. effects of maternal factors and previous lactation Am of Public Health 1986;76:172-7.

21 Willet W. Nutritional epidemiology. New York, Oxford; Oxford University Press, 1990.

22 Bobovnikova T, Dibtseva A, Mitroshkov A, Pleskachevskaya $\mathrm{G}$. Ecological assessment of a region with PCB emissions using samples of soil, vegetation and breast milk: a case study. Sci Total Environ 1993;139-140:357-64.

23 van Casteren V. Inventory of sentinel health information systems with GPs in the European Community. Brussels: Institute of Hygiene and Epidemiology, 1991. 